\title{
Consenting adults? Not necessarily...
}

Companies and scientists in the West are keen to test their drugs in China, which is an important future market. But those running clinical trials need to be on their guard, says David Cyranoski.

n October 2003, China became the first country to move gene therapy into the medical mainstream, when it approved for general clinical use a treatment for head and neck squamous cancer. The feat was a symbol of the country's biomedical ambitions, and was lauded in the Chinese media.

But just a few months later, a story emerged that revealed a grimmer aspect of China's rapid development in biomedicine. In January, four HIV-positive farmers from Henan province, representing a further 15 , sent a letter of complaint to the US National Institutes of Health and the Chinese Ministry of Health. They had participated in a clinical trial for a drug called VGV-1, and claimed that informed-consent procedures had been neglected.

The farmers are among hundreds of thousands of people in Henan infected with HIV by unhygienic commercial blooddonation practices during the 1990s. They say that they were not told about the risk of side effects from VGV-1, and are now consulting lawyers about a possible claim for compensation against Beijing's Ditan Hospital, which ran the trial - and possibly also against Viral Genetics of Azusa, California, the company that supplied the drug.

The episode is a sign that China's clinical research is jumping ahead of its system for ethical oversight. As Nature discovered on a recent visit, awareness of ethical regulations and informed-consent procedures is alarmingly low - even among researchers and medical professionals. Some institutional review boards (IRBs), which are supposed to enforce ethical standards, do little more than rubber-stamp the proposals that come before them. Xiaomei Zhai, a bioethicist at Peking Union Medical College, and a member of several IRBs, admits that many boards need to be better trained. ${ }^{\alpha}$ Otherwise we can't deal with the complicated problems that come up," she says.

There's a great deal of work to be done if China's biomedical researchers are to retain their people's trust as they stride into the clinic with experimental treatments. In the meantime, Western organizations collaborating on clinical-research projects in China will need to take extreme care if they are to avoid getting their fingers burned like Viral Genetics. The company trusted its Chinese partners to deal with the regulatory and ethical aspects of the VGV-1 trial. Instead it has seen its name tarnished by the revelation that the project went ahead without approval from the State Food and Drug Administration (SFDA), which is supposed to check previous data to confirm that experimental drugs don't pose unacceptable hazards.

\section{Land of opportunity}

Despite the potential pitfalls, medical researchers are queuing up to work in China because of the plentiful dinical opportunities. Companies are also eyeing the long-term prospects of selling drugs into an emerging pharmaceuticals market. From rare genetic disorders, through obesity and other 'lifestyle' ailments, to a wide range of infectious diseases, China has one of the most complicated and debilitating disease profiles of any nation.

In theory, regulations put in place in 1999 mean that clinical trials in China must abide by Good Clinical Practice, a set of international standards that demand informed consent, approval of trial protocols by independent IRBs and the appropriate regulatory authorities, plus strict monitoring of ongoing trials. But in practice, enforcement of these standards is patchy. And unlike Western regulations, the Chinese rules contain no detailed guidelines on procedures for recruiting volunteers and ensuring informed consent. "We need details on the possibility of damage to subjects and about compensation," says Yiming Shao, a virologist at the National Center for AIDS/STD Prevention and Control in Beijing, who advises the Chinese government on publichealth issues.

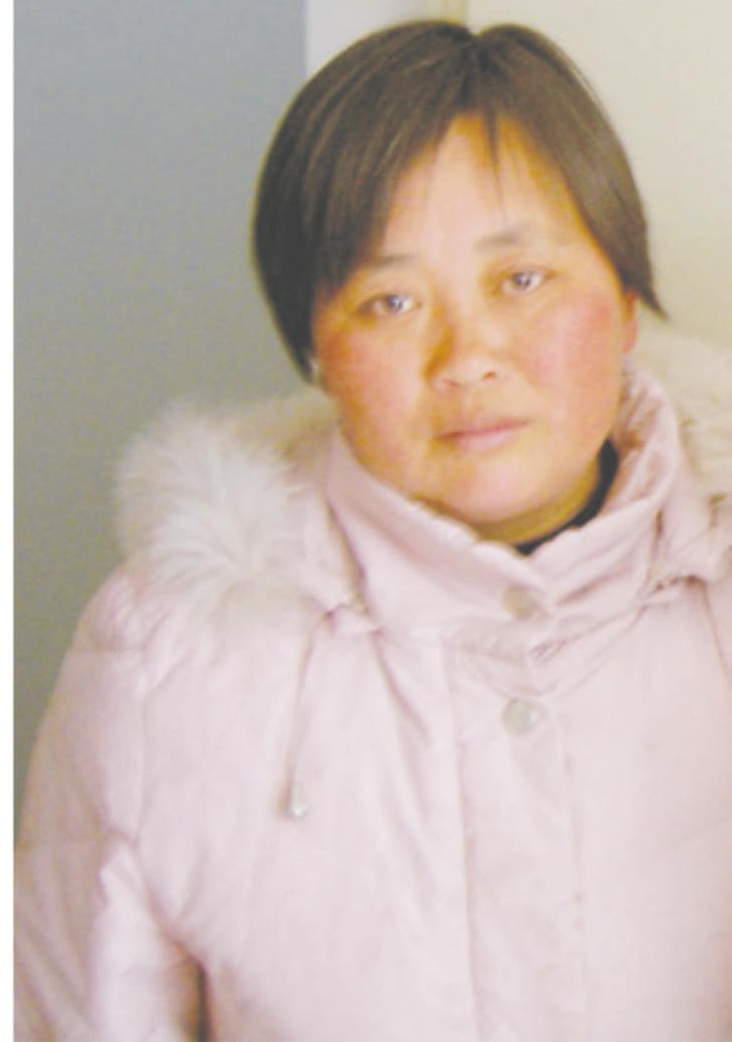

IMAGE UNAVAILABLE FOR COPYRIGHT REASONS
What's more, a few diseases are deemed sufficient threats to public health that even some of those who are trying to tighten China's ethical framework are prepared to continue cutting corners. HIV, which could infect 10 million Chinese in the coming decade, heads this emergencylist. "For AIDS, 
helped by the lack of any national IRB accreditation system.

Wang's IRB is one of the best regarded in China. Yet even its meetings are an eye-opening experience for anyone familiar with international standards - as Nature found out by attending a lively session in March. The committee evaluated eight proposals for new trials, three of which - including one collaboration with a US institution detailed few or no procedures for informed consent. With a mix of laughter and censure, Wang's IRB interrogated the researchers. One scientist, realizing that her trials with children would require parental approval, thought that this should be enough. "She wanted to know whether approval from the children was also necessary, says Wang. His committee sent that proposal back to the drawing board.

Worryingly, such rulings may not have the desired effect of forcing researchers to adopt more rigorous ethical standards." If we reject them, they often just go somewhere else,"says Wang.

\section{Paper trail}

Procedures common in other countries, Xiuping Li (left) and firong Pang say they weren't told of risks when they took part in an AIDS drug trial.

we have to accept that we have to compromise," saysZhai.

Such sentiments help explain how the VGV-1 trial fell into an ethical mire. VGV-1 consists of two proteins derived from calf thymus glands that, in lab tests, bind to an HIV protein called gp41. The idea is to prevent the virus from latching on to its target cells. A previous trial on ten patients in Mexico hinted that VGV-1 could restore the effectiveness of other AIDS drugs (J. J.AyalaGaytán et al. HIV AIDS Rev. 3, 8-13; 2004). The Chinese trial was designed to study the drug's effects in patients who had received no other antiretroviral therapy.

\section{Recruitment drive}

Trial participants tell alarming stories of how they were recruited. Xiuping $\mathrm{Li}$, a farmer from Henan, claims she was told that the series of injections would put her in good health for 20 years without further treatment. "They didn't say that there were risks," she daims. Jirong Pang, another participant from Henan, says he suffered a high fever and red flaky rash all over his body and face. Other patients had more severe reactions, alleges $\mathrm{Li}$, and were forced to pay for additional medicine to treat them.

Participants interviewed by Nature say they signed informed-consent forms that they could not understand and that doctors made no effort to explain. Their complaints go on: copies of the forms had to be paid for; expenses were not covered as agreed; participants weren't informed of the trial's results, despite asking. "That's common in China.
Most doctors don't answer patients' questions," says Fei Zang, a former accountant from Beijing who volunteered for the trial.

The patients' complaints were referred to the IRB of the National Center for AIDS/STD Prevention and Control. It recommended that, in future, doctors must make better efforts to explain trials to patients, and ruled that the 48 yuan (US\$5.80) charged for informed-consent forms should be returned and that participants should be paid expenses at a rate of 10 yuan per day. But overall, the panel concluded that there were no ${ }^{\text {"serious problems }}{ }^{n}$ with the trial-much to the disappointment and anger of the participants.

Ruotao Wang, an epidemiologist at the Union School of Public Health in Beijing, who chairs the National Center for AIDS/STD Prevention and Control's IRB, explains that his remit didn't include the failure to get the drug approved for experimental use by the SFDA. "That's a serious problem," he says. The fact that the trial was approved by Ditan Hospital's IRB despite this omission underlines the inadequacy of the current framework for ethical oversight.

Zhai says that her IRBs would never authorize a trial without SFDA approval - but she understands how it might happen elsewhere. "A US company says it has medicine, and doctors say this is good news," Zhai says. On hearing this, inexperienced members of many Chinese IRBs may get carried away with enthusiasm. "Few have formal training in bioethics," says Zhai. "They are mostly scientists." Matters aren't such as journal policies that stipulate ethical procedures, are also absent in China. "Most journals in China give no consideration to ethical matters," says one editor, who is adding notices of informed-consent procedures to his journal pages in an attempt to raise awareness among potential authors. ${ }^{\alpha}$ But if we followed international practice seriously, we would receive very few papers," he says.

Against this chaotic background, researchers from Western institutions can find themselves battling charges of impropriety even if they have satisfied international ethical requirements. David Ho, director of the Aaron Diamond AIDS Research Center in New York, who is conducting a trial of a combination of antiretroviral drugs in Yunnan province, has come under attack for not getting provincial ethical backing - even though wellregarded IRBs in Beijing and the United States approved the protocol. "Some people do not want us in China, "claims $\mathrm{Ho}$, who was born and raised in Taiwan. "They want to slow our programmes down because I am viewed as a foreigner."

Viral Genetics, meanwhile, is still counting the cost of its foray into the wilds of Chinese cinical research. "We appreciate the fact that perception of the trial may be tainted because of a bureaucratic mistake," says Alan Sheinwald, who handles public relations for the company."But we believe that the underlying ethical, medical and scientific practices are up to any scrutiny that has been or will be brought to bear." That assertion may yet be tested in a court of law.

David Cyranesk is Nature's Astan-Pacinic comespondent. 